\title{
Contribution and Performance of Indian Psychiatrists and a Pan-Indian Psychiatry Journal to Mental Health Literature during 2010-14
}

\author{
Anusa Arunachalam Mohandoss ${ }^{1}$, Rooban Thavarajah² \\ ${ }^{1}$ Department of Psychiatry, Shri Sathya Sai Medical College and Research Institute, Ammapettai, Kanchipuram, Tamil Nadu, INDIA. \\ ${ }^{2}$ Marundeeshwara Oral Pathology Services and Analytics, CS4, Bay Breeze Duraisamy Apts, 119 East Coast Road, Tiruvanmiyur, Chennai, \\ Tamil Nadu, INDIA.
}

\begin{abstract}
Introduction: The quality and quantity of manuscript contribution by Indian Psychiatrist and those by Indian Journal of Psychiatry (IJP) has not been assessed till date. Such a data would be helpful for the policymakers and all stakeholders to plan the future outlook of publishing in and by Psychiatrists. Material and Methods: Using previously described method, contribution of Indian Psychiatrists as well as that of IJP was collected from various resources. Also, such details were collected by hand from PubMed, Journal website and cross-checked with Google Page Ranking system via a specialized software. Results: Indian psychiatrists published 350 articles in 2010 that arose to 506 in 2014. Among the articles published in 2007-2009, only $75.14 \%$ were cited within three years while for the period, 2011-13, only $20.36 \%$ were cited. In the same time frame, manuscript published in IJP garnered $29.07 \%$ and $39.76 \%$. Discussion: IJP is increasingly getting cited surpassing the other journals and nearly 2.5 times of the general medical field. Besides citation, the other quality parameters of IJP are being discussed. Increasing the quality of Indian psychiatrist research output will require a structured and planned program. The manuscript would aid to chalk future policy of research promotion among Indian Psychiatrists.
\end{abstract}

Keywords: Mental Health, India, Psychiatry, Google, Bibliometrics, Indian Journal of Psychiatry, Citation.

\section{INTRODUCTION}

The scientometrics or the science of studying science, information of medical sciences in India is reported to be inadequate in terms of scope and quality. ${ }^{1,2}$ Citations and reach of journals is often estimated by the number of citations within the prescribed time frame besides several other formats. Though not an accurate measure, number of citations within the prescribed time frame are proxy

\section{*Address for correspondence:}

Dr. A. M. Anusa, Assistant Professor, Department of Psychiatry, Shri Sathya Sai Medical College and Research Institute, Ammapettai, Kanchipuram, Tamil nadu, India.

E-mail : anusamd@gmail.com

Phone number : +91-9487619658

\begin{tabular}{|c|c|}
\hline \multicolumn{2}{|c|}{ Access this article online } \\
\hline Official Publication of & \\
\hline & www.jscires.org \\
\hline 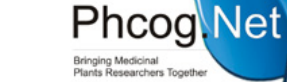 & $\begin{array}{l}\text { DOI: } \\
\text { 10.5530/jscires.5.2.1 }\end{array}$ \\
\hline
\end{tabular}

formats of indicator of quality. ${ }^{3,4} \mathrm{By}$ the dawn of this decade, the Indian Government's Department of Science and Technology commissioned an in-depth analysis of Indian scientific bibliometrics of the preceding decade to formulate future policies and grants. Unfortunately, the subject of psychiatry was clubbed with psychology, obscuring the ability to distinguish the contribution of Indian Psychiatrists in that report. ${ }^{3}$ There is a dearth of contemporary bibliometry of psychiatric literature contributed by Indians. Such a data would help to concentrate effort, promote research and encourage publications by Indian psychiatrists. Also, it would help journals to focus their future policies. The primary aim of this manuscript's focus is on the contribution of Indian psychiatrists to a sample of recognized health literature database along with a focus of introspection of the primary Indian psychiatry journal - Indian Journal of Psychiatry.

\section{Objective of the Study}

The objective of the present study was to assess the Indian Psychiatrists authored publication metrics (as 
in Scopus database) with a focus on the description of the various other metrics as well as their trend in relation to Indian Journal of Psychiatry (IJP). This journal was chosen, as this journal is in existence for nearly seven decades and is unanimous voice of Indian psychiatrists. The Indian Journal of Psychiatry is the official publication of the Indian Psychiatric Society and is currently published by Medknow, part of Wolters Kluwer Health Publishers. The journal was established in early 1949 as the Indian Journal of Neurology and Psychiatry and metamorphosed to present state in 1958. Over the years the journal has been nurtured by several editors.

\section{MATERIALS AND METHODS}

Using Scopus database, as a representative database, it was accessedvia the www.scimagojr.com, as previously described by Rooban et al., ${ }^{4}$ Basic bibliometric data were collected for the past 5 years (2010-14). Scimago has a unique algorithm and based on Scopus database. ${ }^{4}$ The collected data included total number of documents and percentage of international collaboration. Also, for baseline comparison, overall medical stream contributionswere collected. Descriptive data are presented. Data of manuscripts published in Indian Journal of Psychiatry (IJP) was collected from scimago database, Pub med database, a proprietary Google scholar based software - publish or perish (www.harzing.com), those provided by publisher at www.medknow.com (tools - citation analysis) and those handpicked from the issues of the journal. Immediacy index as projected by the IJP publisher, percentage of international collaboration were collected.

Data of the percentage of manuscripts that were cited at least once in the preceding three years were collected from Scimago for medical field, psychiatry, from IJP and using Harzing's software. Harzing's software employs unique Google page ranking system wherein citations from all sources as cited in Google, using unique algorithm were collected. By hand search, from IJP table of contents and journals, total manuscripts from original research, review, brief communications and case reports were categorized as laid down in the table of contents of IJP. Other formats were categorized as "others". The bibliometric values of IJP, using Google scholar for the period 2010 to 2014 (both year inclusive) are presented.

The number of authors and citation patterns were then estimated based on the data. The mean cites per year (total citation received by number of years since published) were calculated for manuscripts published with IJP during the period and tabulated.

The overall score of IJP, namely, Scimago journal rank (SJR- a measure of all parameters coupled to form a single score by Scimago), Source Normalized Impact per Paper (SNIP - Measures contextual citation impact by weighting citations based on the total number of citations in a subject field) and Impact per Publication (IPP- Measures the ratio of citations in a year $(\mathrm{Y})$ to scholarly papers published in the three previous years (Y-1, Y-2, Y-3) divided by the number of scholarly papers published in those same years (Y-1, Y-2, Y-3)) for the period of 2010-14 were collected from www.journalmetrics.com which heavily relies on Scopus database. All the descriptive results are presented and discussed.

\section{RESULTS}

The table-1 shows the total number of citable documents published by Indian psychiatrists and all medical professionals during the study period. The quantity of the publications is increasing with years. However, the rate of publication by Indian psychiatrist is relatively slower as compared to other medical fraternity (combined). Interestingly, in 2010, Indian psychiatrists collaborated more often (twice) than other peers with International researchers. However, this phenomenon slowed down in 2014.

In the medical stream, the total number of cited manuscripts (in the preceding three years) was progressively diminishing. In 2014, about $83.9 \%$ of manuscripts published during 2011-13 were never cited while the $79.7 \%$ of papers by Indian psychiatrists were never cited.

In IJP, in every year of the study period, there is a huge difference in the number of manuscripts published between Scimago (Scopus database), Pubmed listing, Google listed; publisher listed and as handpicked from journal. The same is listed in Table-1. The immediacy index or the rapidity (within the same year) of the manuscript being cited as a ratio of total publication in the year is also listed in Table-1. Similarly, the percent of International collaboration of overall medical field, Indian psychiatrist as well as observed in IJP are presented in Table-1.

Table- 2 describes the percentage of cited documents in a three year period as described by Scimago-Scopus database as well as by Harzing's software. Table-3 gives a perspective of the type of manuscripts in the IJP during 
the study period. Interestingly, 97 letters to editors have been published in the study period as opinion pieces

The citation metrics of the IJP was carefully scrutinized. There were 683 manuscripts published in IJP during the period 2010-14. Using prescribed methods to remove duplication of citations, the citation database was cleared and the overall score of IJP during 2010-14 was calculated using the journal impact option. It was also identified that there were 223 papers in IJP with single author, 160 manuscripts with 2 authors, 138 manuscripts with 3 authors, 125 manuscripts with 4 authors and 37 with more than 4 authors.

It was observed that during the study period, 216 of the 683 manuscripts were never cited and 107 manuscripts received only 1 citation. Only 85 papers received more than 10 citations. Considering the mean cites, it was observed that only 4 papers received, more than 10 citations per year. To assess the overall performance of IJP, the SNIP, IPP and SJR were assessed during the study period and result tabulated in Table 7.

\section{DISCUSSION}

Medical journals of professional societies began as a tool for dissemination of pertinent information and newer evidence based science to all members of society. Today, publishing in such journals is considered essential for promotion, tenures, grants and numerous other professional requirements. ${ }^{4}$ Assessing the quality of such published material is increasingly becoming difficult. Focused bibliometric studies would offer a chance of introspection to all stake holders engaged in publishing Bio-Medical journals so as to improve themselves for betterment.

The results of this study indicate that in the representative Scopus database, Indian psychiatrists, contributes as little as $2 \%$ to India-originated medical literature. As a major stake holder in mental health segment, Indian psychiatrists need to increase their contribution. Also, though the quantity of publications keeps increasing with every passing year, still a substantial number, nearly 4 out of every 5 publications by Indian psychiatrists remained uncited in Scopus database within the first three years of its publication. This is an emergency situation and warrants attention as outlined by the previous recommendations. $3,4,5$ The performance of psychiatric and psychology related manuscripts in high rated journal was deemed to be low in par with International standards but relatively on the higher end among pan-India medical literature at the same time period. ${ }^{5}$ The policy framers, academicians and the professional fraternity need to pitch in to re-evaluate the scope of their research output to turn them to be a high valued one. In this regard, immediacy index, a reflection of the rate of being cited within the published year time frame is critical. The IJP is performing well in the study period as its immediacy index is slowly climbing higher with every year.

The difference between the numbers of manuscripts published in IJP is probably due to methodology employed by the various agencies. This highlight the urgency to bring out a regular, standardized format in IJP adhering to International standards so that most of the manuscript published in IJP gets their due recognition across the indexing and abstracting agencies. Also, the high discrepancy in 2010 is probably due to the time at which the IJP was inducted in to Scopus/Pubmed. The number of manuscripts published in IJP is widely fluctuating. On the contrary, the contribution of Indian Psychiatrist to Scopus data base is constantly increasing. IJP contributed to nearly two third of Scopus listing in 2010 which has decreased to one fifth in 2014. This phenomenon could be due to Indian psychiatrists publishing in other Scopus Indexed Journals.

As seen in Table-2, the percentage of cited manuscripts published in IJP as well as those by Indian psychiatrists in Scopus database is steadily decreasing. On the contrary, analysis using Harzing's software using Google Page ranking at Google Scholar, indicate that about 3 in 4 manuscripts of IJP are being cited. This reflects that though not cited in Scopus, most of the IJP manuscripts are being cited in journals listed with other databases. However, as seen in Table 5 and 6, still, 216 papers of the 683 paper were never cited. In spite of this short coming, IJP still enjoys high bibiliometric score as seen in Table-4.Previous few studies indicate and concur that a substantial part of manuscripts published in IJP were never cited. ${ }^{6,78}$ Part of our result, especially pertaining to numbers of manuscripts and International collaboration in IJP are in concurrence with recently published study. ${ }^{9}$

The steady growth of overall scores of IJP, as reflected by immediacy journal, SJR, IPP, SNIP indicates that IJP as a psychiatry journal is gaining frontiers and enjoying success in all spheres. But in terms of garnering citations in global databases such as Scopus, still IJP has a long way to go. Furthermore, agencies such as the Department of science and technology and indexing agencies need to be impressed upon to delineate psychology and psychiatry as different streams so that the contributions may 
Table 1: Citable documents, immediacy index, international collaboration as reflected by Indian Psychiatrists and Indian Journal of Psychiatry

\begin{tabular}{|c|c|c|c|c|c|c|c|c|c|c|c|}
\hline & \multicolumn{7}{|c|}{ Total number of citable documents } & \multirow{3}{*}{$\begin{array}{l}\text { Immediacy } \\
\text { Index }\end{array}$} & \multicolumn{3}{|c|}{ Percent of International collaboration } \\
\hline & \multirow{2}{*}{$\begin{array}{l}\text { Medical } \\
\text { field }^{1}\end{array}$} & \multirow[t]{2}{*}{ Psychiatry $^{1}$} & \multicolumn{5}{|c|}{ IJP } & & \multirow{2}{*}{$\begin{array}{l}\text { Medical } \\
\text { Field }^{1}\end{array}$} & \multirow[t]{2}{*}{ Psych iatry ${ }^{1}$} & \multirow[t]{2}{*}{ IJP1 $^{1}$} \\
\hline & & & 1 & 2 & 3 & 4 & 5 & & & & \\
\hline 2010 & 16,332 & 350 & 89 & 153 & 209 & 178 & 212 & 0.056 & 15.16 & 30.571 & 15.73 \\
\hline 2011 & 19,570 & 346 & 86 & 86 & 97 & 63 & 92 & 0.175 & 14.323 & 28.902 & 12.79 \\
\hline 2012 & 22,065 & 433 & 102 & 101 & 104 & 64 & 105 & 0.328 & 14.711 & 21.94 & 8.82 \\
\hline 2013 & 23,663 & 533 & 149 & 153 & 158 & 118 & 153 & 0.364 & 15.408 & 21.388 & 10.07 \\
\hline 2014 & 23,264 & 506 & 100 & 103 & 115 & 64 & 106 & 0.125 & 16.425 & 26.68 & 10 \\
\hline
\end{tabular}

1 - from Scimago; 2 - from PubMed; 3 - using Harzing's software; 4 - Publisher provided at www. medknow.com; 5 - Hand picked from journal

\section{Table 2: Percent of cited documents}

\begin{tabular}{ccccc}
\hline & \multicolumn{3}{c}{ Percentage of Cited documents } \\
\cline { 2 - 4 } & \multicolumn{3}{c}{ Scimago } & $\begin{array}{c}\text { IJP } \\
\text { performance } \\
\text { in Harzing's }\end{array}$ \\
\cline { 2 - 4 } & Medical field & Psychiatry & IJP & 84.82 \\
$2007-09$ & 72.20 & 75.14 & 29.07 & 75.26 \\
$2008-10$ & 66.19 & 70.81 & 38.29 & 73.98 \\
$2009-11$ & 57.41 & 65.36 & 38.31 & 72.03 \\
$2010-12$ & 42.39 & 51.03 & 40.79 & 76.69 \\
$2011-13$ & 16.10 & 20.36 & 39.76 & \\
\hline
\end{tabular}

Table 3: Types of manuscript in Indian Journal of Psychiatry

\begin{tabular}{cccccc}
\hline & $\begin{array}{c}\text { Original } \\
\text { research }\end{array}$ & Review & $\begin{array}{c}\text { Brief } \\
\text { communications }\end{array}$ & $\begin{array}{c}\text { Case } \\
\text { reports }\end{array}$ & Others \\
\hline 2010 & 27 & 4 & 3 & 7 & 171 \\
2011 & 23 & 2 & 8 & 13 & 46 \\
2012 & 26 & 2 & 5 & 10 & 62 \\
2013 & 43 & 37 & 8 & 13 & 52 \\
2014 & 25 & 4 & 3 & 20 & 54 \\
\hline
\end{tabular}

Table 4: Bibliometric score of Indian Journal of Psychiatry from 2010 to 2014 using Harzing's Software using Google Scholar database

Total number of papers: This is simply the number of papers returned by Google Scholar or Microsoft Academic

Search in reply to a query.

Total number of citations: The sum of the citation counts across all papers.

Average number of citations per paper: The sum of the citation counts across all papers, divided by the total number of papers. The median and mode are also calculated.

Average number of citations per author: For each paper, its citation count is divided by the number of authors for that paper to give the normalized citation count for the paper. The normalized citation counts are then summed across all papers to give the average number of citations per author.

Average number of citations per author per year: This is the average number of citations per author as above, divided by the number of years covered by the result set.

Average number of papers per author: For each paper, 1/author count is calculated to give the normalized author count for the paper. The normalized author counts are then summed across all papers to give the average number of papers per author.

Average number of authors per paper: The sum of the author counts across all papers, divided by the total number of papers. The median and mode are also calculated.

$h$-index: A Psychiatrist has index $h$ if $h$ of his/her $N_{p}$ papers have at least $h$ citations each, and the other $\left(N_{p}-h\right)$ papers have no more than $h$ citations each.

Egghe's g-index

Zhang's e-index

Contemporary h-index

Hirsch $a=6.17, m=4.40$; Contemporary $a c=5.70$

hl-index

$\mathrm{hl}$,norm: Lifetime $\mathrm{h}$-score that is given by the $\mathrm{h}$-index

Average annual increase in individual $\mathrm{h}$-index

hm-index

AW-index: the square root of the AWCR

Age-Weighted citation rate

Age-Weighted citation rate per author
683

2988;

Cites per year -597.60

$4.37 / 2.0 / 0$

(mean/median/mode)

1454.69

290.93

387.65

$2.40 / 2.0 / 1$

(mean/median/mode)

$22(24 \%)$

$29(29 \%)$

15.26

26

8.49

15

3.00

16.42

31.03

963.08

450.04 


\begin{tabular}{|c|c|c|}
\hline Citations & No. of papers & Citations accumulated \\
\hline 0 & 216 & 0 \\
\hline 1 & 107 & 107 \\
\hline 2 to 5 & 182 & 564 \\
\hline 6 to 10 & 92 & 691 \\
\hline 11 to 15 & 49 & 634 \\
\hline 16 to 20 & 13 & 233 \\
\hline 21 to 25 & 6 & 162 \\
\hline Above 25 citations & 17 & 597 \\
\hline
\end{tabular}

\begin{tabular}{cc}
$\begin{array}{l}\text { Table 6: Trend of Mean cites received per year for } \\
\text { manuscripts published in Indian Journal of Psychiatry } \\
\text { during 2010-14. }\end{array}$ \\
\hline Mean Cites & Number of Manuscripts \\
\hline 0 & 216 \\
$0.01-1.0$ & 216 \\
$1.01-2.0$ & 97 \\
$2.01-3.0$ & 67 \\
$3.01-4.0$ & 31 \\
$4.01-5.0$ & 16 \\
$5.01-6.0$ & 10 \\
$6.01-7.0$ & 14 \\
$7.01-8.0$ & 3 \\
$8.01-9.0$ & 6 \\
$9.01-10.0$ & 4 \\
above 10.01 & 4 \\
\hline
\end{tabular}

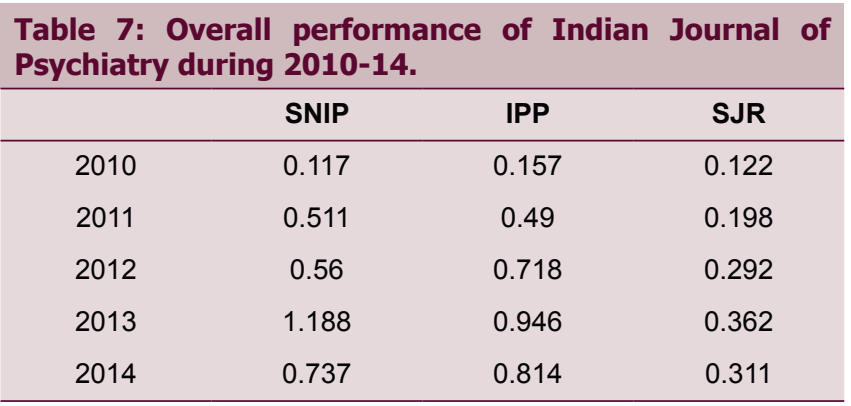

be clearly studied in future by policy making and implementing bodies. National associations and main stream Indian journals also can help in planning, formulating and install training measures for its member to make better manuscripts that are cited more often.

With Indian Medical academicians requiring publications to get promoted in academic career, there is an unprecedented inters in publishing manuscripts in "Indexed" journals. This critical situation may cause a "publish or perish" scenario where many resort to alternate means. ${ }^{10-12}$ In this regard, the positive efforts by the Indian Society of Psychiatrist and the Editor of IJP to provide training via online courses, blogs and at national conferences for novice to write quality manuscripts and do better critical reviewing of peer-reviewed literature, which has begun about a year ago, on a longer run would fetch best results. In addition, potential authors need to educated about guidelines of International committee of Medical Journal Editors (ICMJE - www.icmje.org), Committee on Publication Ethics (COPE - www.publicationethics.org), and the World Association of Medical Editors (WAME www.wame.org) guidelines. Also, they need to be trained to avoid and be aware of intentional and unintentional plagiarism, scientific misconduct, issues with reproducibility of research, importance of negative results, issues surrounding conflict of interest, protection of patient rights in research, open access policy and predatory journals.

The results of this study has to be interpolated very carefully as each of the database - PubMed, Scopus and ranking system such as Google page ranking, Google Scholar and software such as Harzing's have their own merits and demerits. ${ }^{4,13}$ Bridging the outcomes of such varied sources would be out of the scope of the manuscript. However, the numbers indicated in this manuscript, if not accurate, provides a robust estimate and would help the stake holders to arrive at a conservative estimation. The result of the present study can be better read in conjunction, with another study. ${ }^{14}$ The study observed the Relative Citation Ratio (RCR), an article level metric promoted by National Institute of Health, USA reveals the citation pattern of Indian Psychiatrists who have published in PubMed related database. ${ }^{14}$ The higher citation of Indian psychiatrists (as in present study) in the traditional "Grey literature" and relatively lesser RCR calls for an aggressive and need immediate change in policies to promote quality of manuscripts published by Indian psychiatrists en masse.

\section{CONCLUSION}

Robust estimate of popularity and usability of manuscripts published by Indian psychiatrists as well as the manuscripts published in IJP are being recorded for the first time. The results can be used safely by officials for chalking their official policy, providing training formats besides improving the overall quality of manuscripts by Indian Psychiatrists as well as those published in IJP. 


\section{REFERENCES}

1. Mowafi HA. Bibliometric analysis of the volume and visibility of Saudi publications in leading anesthesia journals. Saudi J Anaesth 2012;6(4):393-7. http://dx.doi.org/10.4103/1658-354X.105879; PMid:23494080 PMCid:PMC3591561.

2. Dandona I, Raban MZ, Guggilla RK.Trends of the public health research output from India during 2001-2008. BMC Med 2009;7(1):59. http://dx.doi.org/10.1186/1741-7015-7-59; PMid:19828017 PMCid:PMC2766381.

3. Department of Science and Technology, Bibliometric study of India's scientific publication outputs during 2001-10. New Delhi; www.dst.gov.in/whats_new/whats_new12/report.pdf

4. Rooban T, Madan Kumar P D, Ramachandran S. Contribution of Indian dental research to the Scimago ${ }^{\mathrm{TM}}$ Database during 1996-2007: A preliminary report. Chron Young Sci 2010;1(3):16-21.

5. Rooban T, Madan KP, Poorni S. Indian dental research - need for self appraisal. Indian J Dent Res 2014;25(5):681 http://dx.doi. org/10.4103/0970-9290.147129; PMid:25511075.

6. Andrade C, Choudhury P. Do Indian researchers read Indian research? Indian Journal of Psychiatry 1994;36(4):173-6. PMid:21743697 PMCid:PMC2972499.

7. Bera SC, Sood M, Chadda RK, Sathyanarayana Rao TS. Contributions of general hospital psychiatric units to psychiatric research in India. Indian Journal of Psychiatry. 2014;56(3):278-82. http://dx.doi.org/10.4103/0019-5545.140644; PMid:25316939:PMCid:PMC4181183.
8. Andrade C, Kiran S, Rao SKN, Choudhury P. Do Indian researchers read Indian research? A reappraisal, four years later. Indian Journal of Psychiatry. 2000;42(2):203-8. PMid:21407937 PMCid:PMC2957714.

9. Sivasubramanian G, Vijayakumar P. Bibliometric Analysis of Indian Journal of Psychiatry (2009-2013). Indian Journal of Science, 2015;21(71):92-8.

10. Sukhlecha A. Research publications: Should they be mandatory for promotions of medical teachers?. J PharmacolPharmacother 2011;2(4):221-4. http://dx.doi.org/10.4103/0976-500X.85929; PMid:22025847 PMCid:PMC3198514.

11. Saxena A, Thawani V, Chakrabarty M, Gharpure K. Scientific evaluation of the scholarly publications. JPharmacolPharmacother 2013;4(2):125-9. http://dx.doi.org/10.4103/0976-500X.110894; PMid:23760040 PMCid:PMC3669571.

12. Rooban T, Rao UK, Joshua E, Ranganathan K.Assessing the impact of dental faculties publication - methodology clarifications need of the hour. J Educ Ethics Dent 2013;3(2):49-53. http:// dx.doi.org/10.4103/0974-7761.136042.

13. Falagas ME, Kouranos VD, Arencibia-Jorge R, Karageorgopoulos DE. Comparison of SCImago journal indicator with journal impact factor. FASEB J 2008;22(8):2623-8. http://dx.doi.org/10.1096/ fj.08-107938; PMid:18408168.

14. Mohandoss AA, Thavarajah R. Contribution of Indian psychiatrists to PubMed listed mental health literature during 1995-2013: An exploratory study. Indian J Psychol Med 2016;38(4):302-8 http://dx.doi.org/10.4103/0253-7176.185945;PMid:27570340 PMCid:PMC4980896. 